\title{
O insight na psicanálise
}

\author{
Marcos Chedid Abel ${ }^{1}$
}

RESUMO - Nesse trabalho, questionamos a legitimidade da utilização do termo insight na psicanálise, como sendo adequado, para representar o que se busca numa análise. Discutimos a sua concordância com os princípios que fundamentam a análise e regem a sua prática. Argumentamos, a partir dos sentidos que são indicados por insight, como palavra comum e como conceito psicanalítico.

Palavras-chave: Insight, Freud, psicanálise, efeito terapêutico.

\section{The insight in psychoanalysis}

\begin{abstract}
In this article, we question the legitimacy of the use of the term insight in psychoanalysis, in order to see if it is adequate to represent what is sought by an analysis. We discuss its concordance with the principles that base the psychoanalysis and that regulate its practice. We build up our argumentation from the senses that are indicated in the term insight, as a common word and as a psychoanalytical concept.
\end{abstract}

Key words: Insight, Freud, psychoanalysis, therapeutic effect.

Encontra-se a palavra insight com freqüência, na literatura psicanalítica, como também em textos de autores de outras correntes teóricas. Quando não é inserido nos textos em português na sua forma original, geralmente é traduzido para o português como compreensão interna, compreensão súbita, apreensão súbita, visão súbita, discernimento, perspicácia, pelos neologismos intravisão ou insaite, etc.

1 Psicanalista. Doutor em Psicologia (UnB, 2001), Mestre em Psicologia Clínica (UnB, 1995).

Professor no Curso de Psicologia daFACS/UniCEUB.

E-mail:mc.abel@ig.com.br

Home-page: http://www.marcosabel.tk/ 
Originário, provavelmente, do escandinavo e do baixo alemão, insight é definido na língua inglesa como "a capacidade de entender verdades escondidas, etc., especialmente de caráter ou situação" portando um sentido igual a "discernimento" (Allen, 1990, p. 612). Ou "a capacidade para discernir a verdadeira natureza de uma situação", "o ato ou o resultado de alcançar a íntima ou oculta natureza das coisas ou de perceber de uma maneira intuitiva" (Mifflin, 1994, 'insight').

Insight é a palavra que, em geral, se utiliza nos países de língua inglesa, para traduzir as alemãs Einsicht e Einblick.

Die Einsicht é definida na língua alemã como "uma certa realização que envolve uma conexão complicada” (Languenscheidt, 1999, ,Einsicht'). ${ }^{1}$ E o exemplo apresentado para isso é: "A psicanálise leva a novas Einsichten da psique humana". ${ }^{2}$ Podendo ter também o sentido da "realização de que se fez algo errado", ${ }^{3}$ de "remorso". Como, no exemplo: "Chegar a uma Einsicht", ou "a Einsicht vem depois". ${ }^{4}$ Pode também ser usada no sentido do "processo ou a possibilidade de ver dentro" de alguma coisa. ${ }^{5}$

Der Einblick pode ter o sentido de "uma primeira breve impressão de uma atividade nova, de uma área nova ou da mesma área" (Languenscheidt, 1999, ,Einblick'). ${ }^{6}$ Como também o de "leitura de documentos ou cartas importantes". Ou de ver dentro de uma área física, como em: "ver dentro de um jardim através de uma parede que o obstrui". 8

\section{Insight como conceito}

Na psicanálise, como colocam Sandler, Dare e Holder (1986 [1973]), insight "é usado como se o seu significado fosse facilmente evidente, mas um estudo atento logo revela que o termo compreensão interna (insaite) não está nem um pouco esclarecido" (p. 107).

Citam um irado Bilborg (1952) $)^{9}$ sobre essa questão: "Entre as imprecisões que têm maior repercussão na clínica e que causam a maior confusão está o termo compreensão interna (insaite). Ele veio de parte nenhuma, por assim dizer. Ninguém sabe quem o empregou pela primeira vez, e em que sentido".

Segundo esses autores, insight é um termo que começou a ser utilizado, na psiquiatria geral, desde o início do século XX, "para indicar o conhecimento, pelo paciente, de que os sintomas de sua doença são anormalidades ou fenômenos mórbidos" (Sandler, Dare e Holder, 1986 [1973], p. 107). A ausência de insight é associada, então, principalmente às psicoses.

Consideram que a passagem desse termo da psiquiatria para a psicanálise 
ocorreu principalmente a partir dos anos 50, mas, tendo o seu significado psiquiátrico específico, sido perdido nessa sua extensão.

Ainda segundo esses autores, o primeiro trabalho psicanalítico que teve esse termo em seu título foi de French (1939) sobre Insight and distortion in dreams. ${ }^{10}$ Consideram que French teria sido influenciado por um trabalho do gestaltista Köhler (1925), onde havia descrito "a percepção, por um animal experimental, da forma de resolver um problema" como insight. French teria considerado o insight na psicanálise como um fenômeno similar, isto é, como "uma apreensão útil da situação de conflito". O insight não seria o agente terapêutico per se, mas uma precondição para uma "solução de problema" que pudesse levar à cura (French apud Sandler, Dare e Holder, 1986 [1973], p. 109).

$\mathrm{Na}$ psicologia, a pesquisa de Köhler parece ter realmente marcado indelevelmente o significado do termo. Pois, para um dicionário dessa área, "este termo designa num animal, a capacidade de compreensão súbita de uma situação, no decurso da aprendizagem por ensaio e erro. O termo que melhor lhe corresponderia, em francês, é intuition" (Piéron, 1978 [1951], p. 232).

Em outro dicionário de psicologia, encontramos definição de mesmo teor: "Palavra inglesa sem equivalente em português, sinônimo da palavra intuição, reservada à psicologia humana. Compreensão súbita, por um animal, de uma situação determinada". Também fazendo referência ao trabalho de Köhler:

Após algumas tentativas infrutíferas para alcançar uma banana colocada fora de seu alcance, um chipanzé empilha duas caixas, uma sobre a outra, e utiliza um ramo de árvore à guisa de bastão (Köhler, 1925). Repentinamente, a solução lhe apareceu, sendo os elementos disponíveis reorganizados em função do objetivo pretendido. (Sillamy, s/d, p. 181).

Em um dicionário de filosofia, insight é definido como: "Visão súbita, iluminação, intuição, que permite, por exemplo, ao animal resolver imediatamente um problema" (Lalande, 1996 [1926], p. 1275).

Köhler equivale insight ao que nomeia como "consciência direta da determinação" (Köhler, 1968 [1947], p. 194). Direta, pois independeria de aprendizagem. Como no exemplo que ele fornece:

Depois de uma longa caminhada, em um dia muito quente de verão, bebo um copo de cerveja gelada. Ao fazer isso, sinto na boca a frialdade e um gosto característico. Há também um grande prazer. Será necessário para mim [sic] ficar sabendo, pouco a pouco, que tal prazer provém da frialdade e do gosto? Que ele nada tem a ver com a aranha que estou vendo na parede ou com o tamanho da cadeira que se encontra diante de mim? Evidentemente, não é 
necessária tal aprendizagem. Não estou mais diretamente consciente de meu prazer em si mesmo e do tato e do gosto em si mesmo que estou do fato de que o prazer se refere à frialdade e ao gosto. E sinto que meu prazer é uma reação adequada aos fatos. Entre o prazer e sua base sensorial experimento o que é chamado em alemão seu "verständlicher Zuzamenhang", que corresponde aproximadamente a "relação compreensível" (Köhler, 1968 [1947], p. 1860).

Para Köhler, "o termo insight refere-se à dinâmica experimentada nos campos emocional e de motivação não menos que à determinação experimentada em situações intelectuais". $\mathrm{Na}$ "experiência comum, nada pode ser mais evidente que o discernimento (insight), isto é, a consciência de determinação" (Köhler, 1968 [1947], p. 195).

Como não é nosso objetivo aqui fazer um estudo aprofundado do conceito de insight em Köhler, e sim, apenas apontar a importância desse autor na introdução desse conceito na psicologia, o qual continua firmemente associado ao seu nome, passaremos adiante, buscando apontar como este conceito passou a ser utilizado em psicanálise.

Dessas definições de insight, guardaremos, para usar à frente, principalmente a sinonímia com intuição, e a relação com o experimento de Köhler.

\section{Insight na psicanálise}

Erikson (1964) considera o insight "uma forma de discernimento difícil de definir e mais difícil de defender" (p. 10), e o define como "descoberta psicológica" (p. 36).

Na psicanálise, segundo Sandler, Dare e Holder (1986 [1973]), seria preciso fazer uma distinção entre insight verdadeiro ou emocional, e insight intelectual. Sendo que, para os psicanalistas em geral, "alguma forma de experiência emocional é um acompanhamento essencial do que se considera como compreensão interna (insaite) eficaz". O insight verdadeiro seria aquele que é eficaz. Uma definição que seria tautológica, como reconhecem os autores.

Consideram, divergindo de French, que seria preciso separar o conceito de insight do de cura, pois, na opinião deles, "não se há de concluir que tal compreensão interna (insaite) necessariamente se acompanha de modificações progressivas e terapêuticas no paciente" (Sandler, Dare e Holder, 1986 [1973], p. 110).

Propõem diferenciar o insight intelectual daqueles que "ou liberam emoções ou envolvem algum aspecto de um 'estado afetivo' como parte do conteúdo da compreensão interna (insaite)” (Sandler, Dare e Holder, 1986 [1973], p. 111). 
Minimizam o papel do insight, considerando que:

a modificação terapêutica enquanto conseqüência da análise, depende, em grande medida, da provisão de um esquema referencial conceitual e efetivo, estruturado e organizado, dentro do qual o paciente pode efetivamente situar-se e situar a sua experiência subjetiva de si mesmo e das outras pessoas (Sandler, Dare e Holder, 1986 [1973], p. 111).

Menninger e Holzman (1982 [1973), concedem grande importância ao insight na análise, descrevendo-o como o reconhecimento pelo paciente de que:

1) Este ou aquele aspecto de seu sentimento e atitudes, esta ou aquela técnica de comportamento, este ou aquele papel que ele atribui a outras pessoas, obedece a um padrão;

2) que esse padrão, como a "pegada de um urso que perdeu alguns dedos numa armadilha há muito tempo", imprime-se com cada passo em sua jornada ao longo da vida; está presente em suas relações, na situação da realidade atual, e está presente em sua relação analítica;

3) que esse padrão se originou por uma razão que foi válida na época persistiu apesar das mudanças em algumas das circunstâncias que originalmente o determinaram;

4) que esse padrão contém elementos que são ofensivos e prejudiciais a outras pessoas, assim como onerosos e incômodos para o próprio paciente (Menninger e Holzman,1982 [1973], p. 149).

O insight não consistiria apenas em "ver que algo na situação analítica é semelhante a algo na infância", ou em "ver que algo na infância está refletido nas atividades de sua situação atual", ou ainda em "ver que algo em sua situação atual é um reflexo de algo na situação analítica". Seria "a identificação simultânea do padrão de comportamento característico em todas essas situações, somadas à compreensão dos motivos por que foram e são usados do modo que foram e são" (Menninger e Holzman, 1982 [1973], p. 149).

Os autores colocam que a aquisição de insight faz "recuar a barreira da repressão e dilata a área de autognose". No desenvolvimento da análise, a "barreira da repressão" será repetidamente abordada e "cada vez mais penetrada para a recuperação do material esquecido" (Menninger e Holzman, 1982 [1973], p.151). O paciente estaria num processo de correlação contínua entre as recordações recuperadas, suas atitudes em relação ao médico, e suas fantasias ou sonhos. Propõem uma fómula para esse movimento da análise: Situação da realidade $\rightarrow$ Situação analítica e (ou) de transferência $\rightarrow$ Situação da infância $\rightarrow$ Situação da realidade $\rightarrow$ e assim por diante (Menninger e Holzman, 1982 [1973], p. 151). Dizem que 
"admitimos a importância daquilo a que chamamos insight no processo de recuperação, mas se é um produto ou uma causa da mudança não podemos assegurar" (Menninger e Holzman, 1982 [1973], p. 148).

Greenson apresenta a concepção, também circular, de Kris (1956) do papel do insight na análise. Para este, "o insight conduz a algum benefício terapêutico e o benefício terapêutico conduz a um insight posterior", ou seja, "os insights alteram o ego e estas mudanças tornam possíveis outros insights". O insight seria "o centro de um processo circular, do qual fazem parte também a memória, a função integradora do ego e a auto-imagem” (Greenson, 1982 [1978], p. 254).

Já a opinião do próprio Greenson é que:

Para que um insight seja eficaz, é necessário que seja repetido muitas vezes; interpretações isoladas não produzem mudanças permanentes. Em parte isto se deve ao fato de que os fenômenos inconscientes são condensados; traduzi-los completamente em um conteúdo consciente é complicado e demanda uma quantidade muito grande de tempo. A princípio o paciente não tem usualmente coragem de responder completamente a uma interpretação. Torna-se necessária uma repetição para sobrepujar uma tendência do paciente de afastar afetos, impulsos e fantasias dolorosas. Finalmente, a reiteração do insight dá ao paciente mais oportunidades para dominar a ansiedade e uma chance de ensaiar novos modos de reagir (Greenson, 1982 [1978], p. 269).

Laplanche e Pontalis (1998 [1967], p. 305) apontam uma passagem de Melanie Klein, a título de exemplo, onde ela diz que:

Nossa experiência cotidiana confirma constantemente a necessidade de perlaborar: é assim que vemos pacientes que, em determinada fase, adquiriram insight, recusarem esse mesmo insight nas sessões seguintes; às vezes, até parecem ter esquecido que alguma vez o tenham feito seu. Só tirando as nossas conclusões do material, tal como ele reaparece em diversos contextos, e interpretando-o adequadamente, ajudamos progressivamente o paciente a adquirir insight de forma mais duradoura (Klein, 1961, p. 99).

Klein, portanto, também utiliza o termo insight, considerando a necessidade da sua repetição, para que o paciente o adquira de forma duradoura.

Para Lacan, o insight é uma experiência psicológica de uma operação intelectual que define bastante corretamente o "instante de ver". Que é seguido, na sua concepção, pelo tempo de compreender e o momento de concluir. Os três tempos que constituem o tempo lógico (Lacan, 1973 [1964]). ${ }^{11} \mathrm{O}$ instante de ver ocorreria, quando de uma sutura, uma junção do imaginário e do simbólico (p. 
107).

Na psicoterapia breve de orientação analítica, a proposta é que, por se tratar de uma terapia de curta duração, o insight seja reduzido em sua extensão e profundidade. Ou seja, que se proporcione apenas "experiências iniciais de insight, um autoconhecimento limitado às dificuldades habitualmente contidas no foco terapêutico"; e que este foco seja dirigido principalmente "para as relações do sujeito com os objetos externos de sua vida cotidiana e presente" (Braier, 1986 [1984], p. 29).

Há, portanto, em todos esses usos do termo na psicanálise, como também nesse exemplo da psicoterapia breve de orientação psicanalítica, a relação entre insight e perlaboração (mesmo que não nomeada como tal).

Não há nenhum verbete no Vocabulaire (Laplanche e Pontalis, 1998 [1967]) que corresponda a Einsicht, Einblick ou insight. Encontra-se uma rápida, mas interessante, abordagem à prise de conscience (tomada de consciência) no verbete conscience (psychologique). Já no verbete perlaboration, se referem à "integração de uma interpretação", por meio da perlaboração.

\section{Insight em Freud}

Na Edição standard brasileira das obras psicológicas completas de Sigmund Freud, encontramos sessenta e sete ocorrências da palavra insight. Todas estão entre parênteses e acompanhadas pela tradução "compreensão interna". Esse destaque que é dado à tradução de insight mostra a importância que tem essa palavra para os responsáveis pela versão brasileira. Pelo levantamento que fizemos, essas ocorrências correspondem às localizações de insight na edição inglesa (que, como se sabe, foi a fonte original da versão brasileira).

Já insight na edição inglesa, pelo que pudemos concluir, a partir do cotejamento com a edição alemã, é a tradução adotada para a grande maioria das ocorrências das palavras Einblick ou Einsicht, utilizadas por Freud.

Das ocorrências de insight na edição brasileira, apenas em sete delas, Freud está se referindo ao analisando. Em todas as outras se refere ao analista.

Em relação ao analista, o uso de insight por Freud é associado à idéia de compreensão de uma dificuldade encontrada em um caso específico, ou o vislumbre de um aspecto da teoria mais abrangente. Um exemplo do primeiro desses usos é encontrado no caso do Sr. Forsyth, quando Freud está tratando da telepatia:

Ora, o nome 'Forsyte' desses romances difere pouco do de meu visitante 'Forsyth' e, conforme é pronunciado por um alemão, os dois dificilmente podem ser distinguidos; e há uma palavra inglesa com uma significação - 
'foresight' — que também teremos de pronunciar da mesma maneira e que seria traduzida como 'Voraussicht' ou 'Vorsicht'. Assim, P. realmente selecionara de suas preocupações pessoais exatamente o nome que, ao mesmo tempo ocupava meus pensamentos, como resultado de uma ocorrência da qual ele não tinha conhecimento.Isto parece tomar rumos melhores, concordarão os senhores. Mas penso que ficaremos mais impressionados com o surpreendente fenômeno e até mesmo obteremos uma compreensão interna (insight $)^{12}$ dos seus fatores determinantes se lançarmos a luz da análise sobre duas outras associações apresentadas por P. durante a mesma sessão (Freud, 1933a [1932], p. 66).

Já no sentido da teoria de maneira geral, temos essa passagem, quando Freud diz que:

A psicanálise não tem efeito terapêutico sobre as formas mais graves da perturbação mental propriamente dita. Mas possibilitou - pela primeira vez na história da medicina - uma certa compreensão (insight ${ }^{13}$ da origem e do mecanismo das neuroses e das psicoses (Freud, 1913j, p. 199).

Como também, por exemplo, em:

Aconteceu que nos anos a partir de 1895 fiquei sujeito a duas poderosas impressões que se combinaram para produzir o mesmo efeito sobre mim. Por um lado, alcançara minha primeira compreensão interna (insight $)^{14}$ [os primeiros insights] das profundezas da vida dos instintos humanos; eu vira certas coisas que eram tranqüilizadoras [sérias, que desiludem ${ }^{15}$ e mesmo, de início, assustadoras. Por outro, a comunicação das minhas descobertas desagradáveis teve como resultado a ruptura da maior parte de meus contatos humanos; senti-me como se fosse desprezado e universalmente evitado (Freud, 1941 [1926], p. 315).

Já em outra passagem, relaciona a possibilidade de alguém ter insights da teoria, à experiência própria de análise, quando coloca que: “em geral, é tão difícil proporcionar a quem não é psicanalista uma compreensão interna (insight $)^{16} \mathrm{da}$ psicanálise" (Freud, 1933a [1932], p. 89).

Nas passagens em que se refere ao paciente, em uma especificamente, Freud parece utilizar insight no sentido psiquiátrico que vimos acima. Como capacidade de discernimento, dizendo respeito à função do julgamento. Como na que segue, onde insight é contraposto à surto paranóico: 
No decorrer dos anos seguintes, a irmã que tinha tido essa experiência adoeceu. Passou a se queixar e, por fim, desenvolveu delírios inequívocos de estar sendo observada e perseguida, no seguinte sentido: achava que suas vizinhas tinham pena dela por ter sido abandonada pelo pretenso namorado e por ainda estar esperando que o homem voltasse; estavam sempre a lhe dizer insinuações dessa natureza, diziam-lhe todo tipo de coisas à respeito do homem, e assim por diante. Tudo isso, dizia ela, era naturalmente inverídico. A partir daí, a paciente cai nesse estado somente por algumas semanas de cada vez. Sua compreensão interna (insight) retorna temporariamente e ela explica que tudo isso foi conseqüência de se haver excitado; mesmo assim, nos intervalos, padece de uma neurose que pode ser facilmente interpretada como neurose sexual. E logo cai em novo surto de paranóia. (Freud, 1950a [18871902], p. 292).

Mas, em geral, Freud se refere a uma capacidade requerida ao paciente pela análise, um pré-requisito para o processo analítico, quando diz que "Não se deve esperar que a soma de paciência, adaptabilidade, compreensão interna (insight) e confiança ${ }^{17}$ exigida do paciente e de seus parentes se apresente em muitos outros casos" (Freud, 1918b [1914], p. 23).

Também é utilizada no sentido oposto à de ignorância, como na passagem seguinte:

Na verdade, a pergunta relativa à duração provável de um tratamento é quase irrespondível.Como resultado conjunto de falta de compreensão interna (insight $)^{18}$ por parte dos pacientes e falta de engenhosidade por parte dos médicos, espera-se que a análise atenda às exigências mais ilimitadas, e isso no tempo mais curto. (...) mesmo pessoas inteligentes esquecem que uma proporção necessária tem que ser observada entre tempo, trabalho e sucesso. Isto, incidentalmente, constitui resultado compreensível da profunda ignorância que predomina a respeito da etiologia das neuroses. (Freud, 1913c, p. 170).

Mas, na maior parte das referências ao paciente, a falta de insight é o estado em que este se encontra refratário à continuidade da análise, em um sentido que consideramos ser próximo ao psiquiátrico, como consequiência às resistências. Seja pela transferência positiva erótica:

Não pode haver dúvida de que a irrupção de uma apaixonada exigência de amor é, em grande parte, trabalho da resistência. Há muito notou-se na paciente sinais de uma transferência afetuosa, e pôde-se ter certeza de que a docilidade dela, sua aceitação das explicações analíticas, sua notável compre- 
ensão e o alto grau de inteligência que apresentava deveriam ser atribuídos a esta atitude em relação ao médico. Agora, tudo isto passou. Ela ficou inteiramente sem compreensão interna (insight) ${ }^{19}$ e parece estar absorvida em seu amor. Ademais, esta modificação ocorre muito regularmente na ocasião precisa em que se está tentando levá-la a admitir ou recordar algum fragmento particularmente aflitivo e pesadamente reprimido da história da sua vida. Ela esteve enamorada, portanto, por longo tempo; mas agora a resistência está começando a utilizar seu amor a fim de estorvar a continuação do tratamento, desviar todo o seu interesse do trabalho e colocar o analista em posição canhestra (Freud, 1915a [1914], p. 212).

Seja pela atitude crítica:

Portanto, temos tido a possibilidade de nos convencer de que, em ocasiões incontáveis no decurso de sua análise, a mesma pessoa abandonará sua atitude crítica e depois a reassumirá. Se estivermos na iminência de trazer-lhe à consciência uma parcela de material inconsciente especialmente desagradável, a pessoa se torna extremamente crítica; pode ter empreendido e aceito muitas coisas previamente, agora, todavia, é simplesmente como se aquelas aquisições tivessem sido anuladas; em seu esforço de se opor, a todo custo, pode oferecer o quadro completo de um imbecil emocional. Se, contudo, conseguimos ajudá-la a superar essa nova resistência, ela recupera sua compreensão interna (insight) e entendimento ${ }^{20}$ (Freud, 1916-1917 [1915-1917], p. 345).

O insight intelectual, por si só, não basta na batalha contra as resistências. A força da transferência tem um papel fundamental na decisão do conflito:

A fim de que o paciente enfrente as resistências que lhe mostramos na análise, ele tem necessidade de um poderoso estímulo que influenciará sua decisão no sentido que desejamos, levando à recuperação. De outro modo, poderia acontecer que ele venha a optar em favor da repetição do resultado anterior, e permitiria que aquilo que fora trazido à consciência deslizasse novamente para a repressão. Nesse ponto, o que é decisivo em sua luta não é sua compreensão interna (insight) intelectual ${ }^{21}$ — que nem é suficientemente forte, nem suficientemente livre para uma tal realização - , mas simples e unicamente a sua relação com o médico (Freud, 1916-1917 [1915-1917], p. 518).

Freud também utiliza insight no sentido de uma compreensão espontânea, ocorrendo sem nenhuma relação com a análise, como a que se deu no Homem dos Lobos, em sua infância, quanto à existência da castração: 
Quando estudávamos a gênese da fobia aos lobos, seguimos o efeito dessa nova compreensão interna (insight) do ato sexual ${ }^{22}$; mas, agora que estamos investigando as perturbações da função intestinal, encontramo-nos trabalhando com base na velha teoria cloacal. Os dois pontos de vista permanecem separados um do outro por um estádio de repressão (Freud, 1918b [1914], p. 102).

A única passagem onde encontramos Einsicht não no sentido de uma précondição geral para a análise, mas, como uma consequiência, um ganho por parte do paciente, é na que se segue:

Os pais que tiverem em si a experiência da análise, e muito devem a ela, além de lhe deverem compreensão interna (insight $)^{23}$ das falhas havidas na sua própria educação, tratarão seus filhos com melhor compreensão e lhes pouparão muitas coisas de que não foram poupados (Freud, 1933a [1932], p. 183).

\section{Imagem e palavra}

Insight, como vimos, significa literalmente visão interna. Ou seja, diz respeito ao sentido da visão. Na psicologia da Gestalt, desde os experimentos de Wertheimer, em 1910, sobre o movimento aparente, a visão é o sentido privilegiado. A psicologia da Gestalt foi fundada sobre o sentido da vista. De tal maneira que, na opinião de Koestler (1949), as conclusões derivadas das hipóteses obtidas do estudo da visão seriam mesmo "aplicadas indiscriminadamente a outros processos que o visual" (p. 356).

Entretanto, como ressalta Celes (1997), a vista não é o sentido privilegiado na psicanálise. Nesta, o que é buscado é que o sujeito fale e escute. O objetivo é fazer falar e fazer ouvir. Ou melhor, é "fazer ouvir o que se fala" (p. 25). Na psicanálise, o sentido privilegiado é o da audição, concentrado pela atenção no ato da escuta.

A introdução do divã marca a passagem da observação médica para a escuta analítica. Como coloca Celes (1997), “o divã é o lugar onde não se dá a 'ver', foi instituído para propriamente não 'ver' nada” (p. 46).

A imagem, tal como a onírica, a lembrança encobridora e a alucinação, só dizem algo se for traduzida, ou melhor, transformada, em palavras. Uma imagem diz mais que mil palavras $3 / 4$ mas só se houver palavras para esse dizer. Sobre esta questão, Celes (1997) aponta que: "mesmo quando são imagens, o que ocorre, não se trata de um convite a observá-las, mas de descrevê-las, em todos os detalhes, isto é, trata-se de falar" (p. 46). Isso se dá também do lado do analista, pois uma 
imagem construída no analista pelas palavras do analisando, também precisa ser colocada em palavras. Pois o objetivo psicanalítico de tornar pré-consciente uma "coisa" inconsciente, é alcançado vinculando-a "às representações verbais que lhe são correspondentes"24 (Freud, 1923b, p. 33).

Freud considera que é possível o pensamento com imagens, mas é um modo mais primitivo de pensar:

Não devemos deixar-nos levar, talvez visando à simplificação, a esquecer a importância dos resíduos mnêmicos ópticos, quando o são de coisas, ou a negar que seja possível os processos de pensamento tornarem-se conscientes, mediante uma reversão a resíduos visuais, e que, em muitas pessoas, este parece ser o método favorito. O estudo dos sonhos e das fantasias pré-conscientes, como se demonstra nas observações de Varendonck, pode dar-nos uma idéia do caráter especial deste pensar visual. Aprendemos que o que nele se torna consciente é, via de regra, apenas o tema geral concreto do pensamento, e que as revelações entre os diversos elementos desse tema geral, que é o que caracteriza especialmente os pensamentos, não podem receber expressão visual. Pensar em figuras, portanto, é apenas uma forma muito incompleta de tornar-se consciente. [grifo nosso] De certa maneira, também, ela se situa mais perto dos processos inconscientes do que o pensar em palavras, sendo inquestionavelmente mais antiga que o último, tanto ontogenética quanto filogeneticamente (Freud, 1923b, p. 34).

Mesmo na metapsicologia, a representação topográfica, espacial, do aparato psíquico, é considerada por Freud a mais precária em relação à dinâmica e à econômica, na concordância com o que busca representar.

\section{Três argumentos}

Insight é considerada sinônimo de intuição, conforme as definições apresentadas acima. A palavra intuição também tem, na sua raiz, a presença do sentido da vista. Pois vem do latim intuitio, que significa olhar. É definida como "um modo de conhecimento imediato, apreensão direta, sobre o modelo da visão, da realidade das coisas ou da verdade dos conceitos, por oposição ao conhecimento discursivo ou o raciocínio" (Hachette, 1998, 'intuition'). É “uma apreensão imediata pela mente sem raciocínio" (Allen, 1990, p. 623). Na intuição, se trata de uma "visão direta e imediata de um objeto de pensamento atualmente presente ao espírito e apreendido na sua realidade individual", "todo o conhecimento dado de uma vez e sem conceitos" (Lalande, 1996 [1926], p. 591), ou ainda, "conhecimento 
sui generis, comparável ao instinto e ao senso artístico, que nos revela aquilo que os seres são em si próprios, por oposição ao conhecimento discursivo e analítico que no-los faz conhecer do exterior" (Lalande, 1996 [1926], p. 595).

Portanto, considerando essa sinonímia, apresentaremos três argumentos quanto à inadequação do uso de insight, para nomear o que se passa em uma psicanálise.

Primeiramente, insight diz respeito a um modo de conhecimento que é imediato, ou seja, não progressivo $3 / 4$ o que estaria de acordo com a definição de Köhler apresentada acima. Um acontecimento, portanto, que nos parece próximo daquele modo de revelação mística que parece ocorrer, sem que tenha sido precedida, aparentemente, por qualquer busca ou prática com esse objetivo. Entretanto, na psicanálise, a conscientização é um processo que demanda tempo. Mesmo o que pode se apresentar como um insight, uma revelação súbita, é, na verdade, o resultado de um trabalho (o que já implica a idéia de tempo) nas resistências. Não é algo que se dá espontaneamente, e que se dê de uma vez por todas. Há a necessidade do tempo para as perlaborações.

Em segundo lugar, além desse caráter imediato, outra diferença fundamental entre o que se passa em uma psicanálise e o insight, está no fato deste ser $i$-mediado, isto é, sem a mediação do discurso. Ou seja, o insight não mediado é pela palavra, estando mesmo em oposição ao conhecimento analítico. Enquanto que a psicanálise tem, por instrumento, a palavra, o discurso. Não apenas como meio de trabalho (pela palavra), mas como o próprio material de trabalho (na palavra).

Além disso, intuição está associada à evidência, "plena clareza intelectual" (Lalande, 1996 [1926], p. 596). Que deriva do verbo latino videre, que significa 'ver' (Mifflin, 1994, 'evident'), significando aquilo que "se impõe ao espírito de uma maneira clara e incontestável" (Hachette, 1998, 'évident'). Aquilo que "não oferece dúvida, que se compreende prontamente, dispensando demonstração" (Holanda Ferreira, 1999, 'evidente'). No entanto, na psicanálise o que se tem são indícios, não evidências. ${ }^{25}$ Indícios que, por meio das interpretações, são coligidos, formando as construções. Interpretações e construções cuja única forma possível de confirmação é a indireta. Pois, para o analista, mesmo o que se oferece ao olhar, como o dedo de Dora na sua bolsinha, se constitui como indício. Da parte do analisando, mesmo suas reações transferenciais visíveis $3 / 4$ seja um temor na sua mão ou mesmo um choro $3 / 4$, são também modos indiretos de confirmação. Não são provas diretas que permitam "imediata evidência do fato" (Soibelman, 1998, 'prova direta'), mas, sim, provas indiretas, ou circunstanciais, isto é, formadas a partir de indícios. Isso, porque não é possível se ter um acesso direto ao inconsciente. Somente às suas formações. 


\section{Conclusão}

Portanto, consideramos que o uso do termo insight, em função dessas significações que ele porta e indica, não representa adequadamente o que ocorre em uma psicanálise. Podendo inclusive (des)encaminhar à pratica de uma análise intuitiva, onde é concedida prevalência às imagens e sentimentos que ocorrem no analista, a chamada contratransferência, em detrimento da palavra do analisando. Uma psicanálise fundamentada na adivinhação. ${ }^{26} \mathrm{~A}$ análise, tornando-se um processo misterioso, dependendo de um sexto sentido, tendo no insight, como vimos colocar Erikson (1964), "uma forma de discernimento difícil de definir e mais difícil de defender" (p. 10).

Pensamos que é possível essa modalidade de conhecimento $3 / 4$ o intuitivo. Entretanto, consideramos se tratar de algo diverso do que a psicanálise propõe. Pois o conhecimento intuitivo nos parece mais próximo daquele das práticas divinatórias, tais como a das pítias no oráculo do templo de Apolo, em Delfos, onde é requerido realmente o sexto sentido da intuição.

Freud diz em uma carta a Jung que se considera um intuitivo. Mas um intuitivo disciplinado: "percebo que não fui talhado para a investigação indutiva, que a minha natureza é toda intuitiva e que, ao dispor-me a estabelecer a ciência puramente empírica da psicanálise, submeti-me a uma extraordinária disciplina" (McGuire, 1976 [1974], p. 536). ${ }^{2727}$ Carta de 11/12/1911.

Para finalizar, pensamos que o que se passa em uma psicanálise, está mais próximo da convicção a que se chega na resolução de um jogo de palavras-cruzadas, que do insight de uma Gestalt, ou da súbita iluminação mística.

\footnotetext{
NOTAS:

${ }^{1}$,eine bestimmte Erkenntnis, die einen komplizierten Zusammenhang betrifft”.

${ }^{2}$,Die Psychoanalyse führt zu ganz neuen Einsichten in die menschliche Psyche”.

3 ,die Erkenntnis, dass man Falsches getan hat".

${ }^{4}$,zurEinsicht kommen; (späte)Einsicht zeigen”.

5 , ,der Vorgang oder die Möglichkeit des Einsehens”.

${ }^{6}$,ein erster kurzer Eindruck einer neuen Tätigkeit, eines neuen Gebiets”.

${ }^{7}$,das Lesen von Dokumenten oder wichtigen Briefen”.

${ }^{8}$ „,Mir war der Einblick in den Garten durch eine hohe Mauer verspertt".

${ }^{9}$ Não consta na respectiva bibliografia.

${ }^{10}$ Nãoconstana respectivabibliografia.

${ }^{11}$ «Le temps logique est constitué par trois temps. D

'abord, l'instant de voir $3 / 4$ qui n'est point sans mystère, bien qu' assez correctement défini dans cette expérience psychologique de l'opération intelectuelle qu'est l' insight. Ensuite, le temps pour comprendre. Enfin, le moment de conclure.» (Lacan, 1973 [1964],p.39)

${ }^{12}$ Naedição inglesa, encontra-se realmente a palavra
} 
insight (Freud, 1971 [1932], p. 49), que foi usada para traduzir a alemã Einblick (Freud, 1999 [1932],p. 53).

13 ,einen Einblick"'(Freud, 1999 [1913], p. 390).

${ }_{14}^{14}$,die ersten Einblicke” (Freud, 1999[1926],p.51).

15 “ernüchtern”'(Freud, 1999 [1926],p.51).

${ }^{16}$ Que, naedição inglesa também consta como insight(Freud, 1971 [1932],p. 69), enaalemãEinblick(Freud, 1999[1932],p. 76).

${ }_{17}^{17}$, Einsicht und Zutrauen”(Freud, 1999 [1918],p. 33).

${ }^{18}$ „Einsichtlosikeit”'(Freud, 1999 [1913],p. 460).

${ }^{19}$, ,einsichtslos geworden”(Freud, 1999 [1915],p. 310).

${ }^{20}$,seine Einsicht und sein Verständnis" (Freud, 1999 [1917], p. 303).

${ }^{21}$,seine intellektuelle Einsicht” (Freud, 1999 [1917],p. 463).

${ }^{22}$,derneuen Einsicht in den geschlechtlichen Akt”(Freud, 1999 [1918],p. 111).

${ }^{23}$ Que na edição inglesa também está como insight (Freud, 1971 [1932],p. 150), e na alemã Einsicht (Freud, 1999 [1932], p. 161).

${ }^{24}$ „Durch Verbindung mit den entsprechenden Wortvorstellungen”(Freud, 1999 [1923], p. 247).

25 "Coisa cuja certeza se observa de plano, de imediato. Patente. Que independe de demonstração. Que nãoé passível de dúvida. Evidência: qualidade de evidente. Evidenciar: comprovar, patentear.' (Soibelman, 1994, 'evidente'). "Provas incontestáveis existentes nos autos. Certeza indubitável proporcionada pelas provas existentes nos autos, de que os fatos ocorreram pela forma que elas demonstram. Ocorrência indiscutível de fatos, provada nos autos." (Soibelman, 1994, 'evidência dos autos').

${ }^{26}$ Apesar de que por vezes Freud usa o verbo adivinhar, com frequiência relacionadoà transferência.

\section{Referências}

$\mathrm{Na}$ apresentação das obras de Sigmund Freud, da E.S.B. (Edição standard brasileira das obras psicológicas completas de Sigmund Freud), utilizamos o padrão cronológico estabelecido pelo seu editor inglês James Strachey: a data da primeira edição original, seguida da data do manuscrito entre colchetes, quando estas não coincidem. Já naquelas da Gesammelte Werke, constam a data da edição seguida da data da edição original.

A BÍBLIA SAGRADA (1969). Antigo e novo testamento. Trad. João Ferreira de Almeida. Rio de Janeiro: Sociedade Bíblica do Brasil.

ALLEN, R. E. (1990). The concise Oxford. Oxford: Clarendon Press.

BRAIER, E. (1986 [1984]). Psicoterapia breve de orientação psicanalítica. São Paulo: Martins Fontes.

CELES, L. A. M. (1997). Trabalho e teoria - uma aproximação ao sentido da psicanálise. Seminário de pós-graduação, Universidade de Brasília, Brasília.

ERIKSON, E. (1964). Insight and responsability. New York: Norton.

FREUD, S. (1913c). Sobre o início do tratamento (Novas recomendações sobre a técnica 
da psicanálise I). Em E.S.B. $1^{\text {a }}$ ed. Rio de Janeiro: Imago, s/d. v. XII. (1913j). O interesse científico da psicanálise. Em E.S.B. $1^{\text {a }}$ ed. Rio de Janeiro: Imago, s/d. v. XIII.

(1915a [1914]). Observações sobre o amor transferencial (Novas recomendações sobre a técnica da psicanálise III. Em E.S.B. $1^{\text {a }}$ ed. Rio de Janeiro: Imago, s/d. v. XII.

(1916-1917 [1915-1917]). Conferências introdutórias sobre psicanálise. Em E.S.B. $1^{\text {a }}$ ed. Rio de Janeiro: Imago, 1976. vols. XV e XVI.

(1918b [1914]). História de uma neurose infantil. Em E.S.B. $1^{\text {a }}$ ed. Rio de Janeiro: Imago, 1976. v. XVII.

(1923b). O ego e o id. Em E.S.B. $1^{\text {a }}$ ed. Rio de Janeiro: Imago, 1976. v. XIX.

(1926e). A questão da análise leiga. Em E.S.B. $1^{\text {a }}$ ed. Rio de Janeiro: Imago, 1976. v. XX.

(1933a [1932]). Novas conferências introdutórias sobre psicanálise. Em E.S.B. $1^{\text {a }}$ ed. Rio de Janeiro: Imago, 1976. v. XXII.

(1941 [1926]). Discurso perante a sociedade dos B'Nai B'Rith. Em E.S.B. $1^{\text {a }}$ ed. Rio de Janeiro: Imago, 1976. v. XX.

(1941d [1921]). Psicanálise e telepatia. Em E.S.B. 1ª ed. Rio de Janeiro: Imago, 1976. v. XVIII.

(1950a [1887-1902]). Extratos dos documentos dirigidos a Fliess. Em E.S.B. $3^{\mathrm{a}}$ ed. Rio de Janeiro: Imago, 1990. v. I.

(1971 [1932]). New introductory lectures on psycho-analysis. The standard edition of the complete psychological works of Sigmund Freud. London: Hogart Press and The Institute of Psycho-Analysis. v. XXII.

(1999 [1913]). Das Interesse an der Psychoanalyse. Em Gesammelte Werke. Frankfurt am Main: Fischer Taschenbuch Verlag. v. VIII, p. 389-420.

(1999 [1915]). Bemerkungen über die Übertragungsliebe. Em Gesammelte Werke. Frankfurt am Main: Fischer Taschenbuch Verlag, v. X, pp. 306-321.

(1999 [1917]). Vorlesungen zur Einfürung in die Psychoanalyse. Em Gesammelte Werke. Frankfurt am Main: Fischer Taschenbuch Verlag. v. XI.

(1999 [1918]). Aus des Geschichte einer infantilen Neurose. Em Gesammelte Werke. Vol XII, pp. 27-157. Frankfurt am Main: Fischer Taschenbuch Verlag.

(1999 [1923]). Das Ich und das Es. Em Gesammelte Werke. Frankfurt am Main: Fischer Taschenbuch Verlag. v. XIII, pp. 235-290.

(1999 [1926]). Ansprache an die Mitglieder des Vereins B'Nai B'Rith. Em Gesammelte Werke. Frankfurt am Main: Fischer Taschenbuch Verlag. v. XVII, pp. 51-58.

(1999 [1932]). Neue Folge der Vorlesungen zur Einführung in die Psychoanalyse. Em Gesammelte Werke. Frankfurt am Main: Fischer Taschenbuch Verlag. v. $\mathrm{XV}$. 
GREENSON, R. (1981 [1967]). A técnica e a prática da psicanálise. Rio de Janeiro: Imago. v. 1. (1982 [1978]). Investigações em psicanálise. Rio de Janeiro : Imago. v. 1.

HACHETTE (1998). Dictionnaires français. Paris: Hachette livre. CD-ROM.

HOLANDA FERREIRA, Aurélio Buarque (1999). Novo dicionário da língua portuguesa. Rio de Janeiro: Nova Fronteira. CD-ROM. Versão 3.0.

KOESTLER, A. (1949). Insight and outlook - an inquiry into the common foundations of science, art and social ethics. New York: MacMillan.

KÖHLER, W. (1925). The mentality of apes. Nova York : Harcourt, Brace \& World Inc. (1968 [1947]). Psicologia da Gestalt. Belo Horizonte: Itatiaia.

KRIS, E. (1956). On some vicissitudes of insight in psycho-analysis. International Journal of Psycho-Analysis. v. 37, p. 445-446.

LACAN, J. (1973 [1964]). Les quatre concepts fondamentaux de la psychanalyse. Em Le séminaire, Livre XI. Paris: Seuil.

LALANDE, A. (1996 [1926]). Vocabulário técnico e crítico da filosofia. São Paulo: Martins Fontes.

LANGUENSCHEIDT (1999). PC-Bibliothek. Langenscheidt KG. CD-ROM. Versão 2.02.

LAPLANCHE, J. e PONTALIS, J.-B. (1998 [1967]). Vocabulaire de la psychanalyse. Paris : Quadrige/PUF.

McGUIRE, W. (Org.) (1976 [1974]). Freud/Jung - Correspondência completa. Rio de Janeiro: Imago.

MENNINGER, K. \& HOLZMAN, P. (1982 [1973]). Teoria da técnica psicanalítica. Rio de Janeiro: Zahar.

MIFFLIN, H. (1994). The American heritage dictionary. EUA: SoftKey. CD-ROM. Versão $3.6 \mathrm{a}$

PIÉRON, H. (1978 [1951]). Dicionário de psicologia. Porto Alegre: Globo.

ROBERT, P. (1996-1997). Le nouveau Petit Robert. Paris: Dictionnaires Le Robert. CDROM. Versão 1.3.

SANDLER, J., DARE, C. \& HOLDER, A. (1986 [1973]). O paciente e o analista fundamentos do processo psicanalítico. Rio de Janeiro: Imago.

SILLAMY, N. (s/d). Dicionário de psicologia. Larousse do Brasil.

SILVEIRA BUENO (1980). Dicionário escolar da língua portuguesa. Rio de Janeiro: FENAME.

SOIBELMAN, L. (1998). Enciclopédia jurídica. Ed. Elfez. CD-ROM. 